\title{
A metacognição na abordagem algébrica do material didático do Gestar II
}

\section{The metacognition in the algebraic approach of the didactic material from Gestar II}

\author{
Luís Renan Leal de Melo \\ luisrenanleal@gmail.com
}

Lúcia de Fátima Araújo

luciaaraujo@hotmail.com

Marcelo Câmara dos Santos

marcelocamaraufpe@yahoo.com.br

\begin{abstract}
Resumo
Esta pesquisa teve por objetivo investigar o material didático de Matemática do Programa Gestão da Aprendizagem Escolar, o Gestar II. O referido programa de formação continuada é voltado para professores em serviço nos anos finais ( $6^{\circ}$ ao $9^{\circ}$ ano) do ensino fundamental em escolas públicas do Brasil e visa elevar a competência de professores e alunos. Nossa pesquisa investigou as atividades de álgebra presentes nos Cadernos de Atividades de Apoio à Aprendizagem (AAA) do Gestar II. Como aporte teórico, fundamentamo-nos no conceito de metacognição, compreendido como a capacidade que o sujeito da aprendizagem tem de refletir sobre a própria cognição (dimensão metacognitiva de conhecimento) e de monitorar os próprios processos cognitivos para resolver problemas (dimensão metacognitiva de autorregulação). Assim, investigamos quais estratégias metacognitivas poderiam ser desenvolvidas pelos alunos, na resolução das atividades de álgebra, de acordo com categorias de análise desenvolvidas por Araújo (2009) e Lucena (2013). Das 121 atividades investigadas, identificamos apenas 9 como possíveis promotoras da metacognição, ou seja, aproximadamente $7 \%$. Dessas, 4 foram classificadas como estratégias metacognitivas da ordem do conhecimento, 3 como estratégias metacognitivas da ordem do procedimento e 2 foram classificadas simultaneamente como estratégias metacognitivas da ordem do conhecimento e da ordem da compreensão do problema. Deste modo, constatamos que mais de $90 \%$ das atividades de álgebra contidas nos AAA correspondem a exercícios que propiciam respostas por meio do automatismo.
\end{abstract}

Palavras-chave: Metacognição. Álgebra. Gestar II.

\begin{abstract}
This research aimed to investigate the didactic material of Mathematics from the Management Programme of School Learning, Gestar II. The referred program of continuing education is designed for teachers in service in the final years $\left(6^{\text {th }}\right.$ to $9^{\text {th }}$ grade) of elementary publics school in Brazil and aims to raise the competence of teachers and students. Our research examined the algebra activities contained in the Learning Support Activities Books (AAA) of the Gestar II. The theoretical approach was based on the concept of metacognition, understood as the learners' ability to reflect on own cognition (metacognitive dimension of knowledge) and monitor their own cognitive processes to solve problems (metacognitive dimension of self-regulation). Therefore, we investigated which metacognitive strategies could be developed by students, in solving algebra activities, according to categories of analysis developed by Araújo (2009), and by Lucena (2013). From the 121 activities analysed, we identify only 9 activities as possible promoters of metacognition, or approximately $7 \%$. Of these, 4 were classified as metacognitive strategies referred to knowledge, 3 as metacognitive strategies referred to the procedure and 2 were classified as both metacognitive strategies referred to knowledge and metacognitive
\end{abstract}


strategies referred to problem comprehension. In this way, we found that over $90 \%$ of algebra activities contained in the AAA correspond to exercises that provide answers through automatism.

Keywords: Metacognition. Algebra. Gestar II.

\section{Introdução}

Muitas discussões têm sido levantadas nos últimos anos para tentar compreender os fatores que contribuem para o insucesso da aprendizagem da Matemática na educação básica. Uma das questões que tem chamado a atenção de pesquisadores da educação é a formação inicial dos professores de Matemática.

Segundo Fiorentini (2008), a formação inicial qualitativamente insuficiente de professores de Matemática tem despertado a necessidade de criação de políticas públicas que visem à formação continuada para a melhoria das práticas pedagógicas destes profissionais e, de acordo com Witter, Wuo e Morais (2011, p.81), “no Brasil parece prevalecer a formação continuada junto às escolas onde os docentes atuam ou em cursos de extensão nas unidades universitárias", viabilizando, assim, a formação continuada em serviço.

Seguindo esse modelo de formação continuada, com recursos do Fundo Nacional de Desenvolvimento da Educação (FNDE), o Programa Gestão da Aprendizagem Escolar, o Gestar II, apresenta-se como alternativa para a formação de professores de Matemática e Língua Portuguesa que estão em serviço nos anos finais $\left(6^{\circ}\right.$ ao $9^{\circ}$ ano $)$ do ensino fundamental, nas redes públicas estaduais e municipais, em todo o país. A ideia central do Gestar II consiste na implantação de suas ações nas salas de aulas, pelo próprio professor cursista que nelas leciona, o qual, ao longo do ano letivo, deve fazer uso do material didático proposto pelo referido programa de formação continuada.

Segundo consta na proposta pedagógica do Gestar II (BRASIL, 2008a), o programa tem como foco a atualização dos saberes profissionais, com a finalidade de elevar a competência de professores e alunos, baseando-se na concepção socioconstrutivista de ensino-aprendizagem, orientando-se para a criação de uma nova escola.

Diante de uma proposta tão ousada, e considerando os problemas que permeiam a educação pública brasileira, é natural que se busque compreender até que ponto tal programa de formação continuada poderia realmente contribuir para a melhoria dos processos educacionais, no tocante ao ensino-aprendizagem da Matemática. 
Desse modo, levantamos a seguinte questão: a abordagem algébrica proposta pelo material didático do Gestar II pode favorecer o desenvolvimento de estratégias metacognitivas na resolução de suas atividades?

Tomamos, então, como principal aporte teórico a metacognição. Segundo Araújo (2009), Goti (1998), Jou e Sperb (2006), Ribeiro (2003) e Zimmerman (1990, 2002), um ensino que permita ao aluno o desenvolvimento de estratégias metacognitivas, levando-os a refletirem sobre o conhecimento construído, bem como autorregularem o seu conhecimento durante a resolução de problemas, certamente contribuirá para uma melhor aprendizagem, já que formará alunos com mais autonomia na construção do seu próprio conhecimento.

Partindo do questionamento levantado por Araújo (2009, p.180-181), "será que a forma de apresentação do conteúdo pelo livro didático, pode promover ou afastar os alunos de uma prática metacognitiva?", resolvemos adotar como objeto de pesquisa alguns livros do material didático de Matemática do Gestar II. Nessa direção, investigamos atividades propostas em livros do Gestar II, utilizados pelos professores cursistas em suas aulas de Matemática, a fim de compreendermos se tais atividades podem promover o desenvolvimento de estratégias metacognitivas em suas resoluções.

O material didático de Matemática do Gestar II contém atividades que englobam os diferentes campos do conhecimento matemático inerentes ao currículo do ensino fundamental. Assim, investigamos apenas as questões referentes ao conhecimento algébrico, pois, segundo os Parâmetros Curriculares Nacionais (PCN), "o estudo da Álgebra constitui um espaço bastante significativo para que o aluno desenvolva e exercite sua capacidade de abstração e generalização, além de lhe possibilitar a aquisição de uma poderosa ferramenta para resolver problemas" (BRASIL, 1998, p.115).

\section{Metacognição}

Quando observamos os processos de ensino-aprendizagem em sala de aula, nem sempre podemos afirmar que nos deparamos com situações que viabilizam a reflexão sobre a construção de novos conceitos, pois estes, muitas vezes, são assimilados por repasse automático de professor para o aluno, limitando-se à simples repetição de estratégias para resolução de atividades. Contudo, os processos de aprendizagem não constituem, necessariamente, algo tão simples e mecânico. 
Para uma aprendizagem efetiva, contrapondo esse automatismo, é fundamental que se priorize a reflexão sobre a construção do conhecimento. Nesse sentido, em nosso trabalho, trazemos à luz a importância de (re)conhecermos o papel da metacognição para a promoção de uma aprendizagem reflexiva.

Ao destacar o importante papel da metacognição em aspectos relevantes relacionados à atividade cognitiva de um indivíduo, bem como ao desempenho deste em atividades relativas ao aprendizado escolar, Flavell (1979), considerado o pai da metacognição, referia-se à ela como sendo a reflexão sobre a própria cognição.

Atualmente, embora haja muitas definições para a metacognição, grande parte delas aponta para o conhecimento e a regulação das nossas próprias atividades cognitivas e dos nossos próprios processos mentais.

Com base nos estudos de Araújo (2009), Burón (2002), Goti (1998), Lafortune e Saint-Pierre (1996), Zimmerman (1990, 2002), entre outros, compreendemos a metacognição como sendo a capacidade que um indivíduo tem (e desenvolve) de conhecer ou regular seus próprios processos cognitivos, favorecendo a reflexão sobre a construção de tais processos e sobre o produto destes, estimulando, de forma mais efetiva, a capacidade de avaliar, de concordar, de discordar, de julgar, de gerenciar os próprios pensamentos, de desenvolver ou aprimorar as próprias estratégias de resolução de problemas.

Acerca de tais processos, no domínio educacional, Soro (2001) e Burón (2002) ressaltam duas dimensões da metacognição: a metacognição como o conhecimento das operações mentais e a metacognição como a autorregulação das operações mentais.

A metacognição, enquanto dimensão do conhecimento, refere-se ao que o sujeito sabe sobre o seu conhecimento. Para Murad (2005, p.15), "é a tomada de consciência dos processos e das competências necessárias para a realização da tarefa e do seu produto". Diz respeito ao "saber que" ou "o que se sabe sobre". Assim, de acordo com estudos de Burón (2002), Flavell (1979, 1987), Ribeiro (2003), entre outros, compreendemos a dimensão metacognitiva de conhecimento como sendo a capacidade de refletir sobre "o que se sabe" a respeito de uma determinada atividade; é o conhecimento que se tem sobre os próprios processos cognitivos ou sobre o conhecimento de outros, sobre uma determinada tarefa a ser realizada (como uma questão proposta em sala de aula ou em um livro didático, por exemplo) ou sobre a adequação de ações cognitivas para se realizar esta tarefa. 
A metacognição, enquanto dimensão de autorregulação, refere-se ao "saber como". De acordo com Burón (2002), o saber como diz respeito à capacidade de refletir sobre como desenvolver estratégias adequadas e eficazes de atuação. Desse modo, considerando os estudos de Araújo (2009), Brown (1987), Gerrikaetxebarria (1996), entre outros, compreendemos a dimensão de autorregulação como a habilidade que um indivíduo tem de monitorar as próprias atividades cognitivas antes, durante ou ao término da execução de uma determinada tarefa. Nesse processo autorregulatório, é possível tomar decisões e planejar cada etapa de execução, bem como controlar cada ação durante a realização da tarefa, refletindo sobre a adequação de cada estratégia, sobre os possíveis erros que vierem a ocorrer e sobre a criação de novos meios (se houver necessidade) para iniciar novas estratégias. É possível ainda avaliar se todos os objetivos propostos inicialmente foram alcançados ou se os resultados são realmente satisfatórios. Todo esse processo pode ser realizado pelo sujeito aprendente de forma consciente, porém a busca da solução do problema pode suscitar cada um desses mecanismos sem que o sujeito esteja consciente deles.

Quando falamos em "estratégia" é natural que tentemos pensar em modelos procedimentais prontos, como fórmulas para serem aplicadas, correndo o risco de incorrermos em automatismos. Porém, na literatura metacognitiva, segundo Burón (2002), quando se fala em estratégias metacognitivas nos processos de aprendizagem, os pesquisadores se referem a formas de trabalhar mentalmente para melhorar tais processos.

Compreendemos, então, as estratégias metacognitivas como sendo habilidades básicas, tais como planejamento, monitoramento e avaliação - ações inerentes a processos autorreguladores -, as quais são fundamentais para se obter o controle da aprendizagem.

Quando buscamos uma aprendizagem que favoreça a construção de estratégias metacognitivas para a resolução de problemas, estamos nos referindo à ação consciente e planejada de o aluno desenvolver reflexivamente procedimentos adequados para se alcançar satisfatoriamente os objetivos previamente traçados.

Quando um estudante desenvolve a habilidade de autorregular sua aprendizagem, segundo Zimmerman (1990, 2002), ele passa a ser mais proativo, autônomo e mais seguro nas decisões a serem tomadas durante os processos de execução de tarefas - diferentemente de um estudante que tem uma postura mais passiva diante da aprendizagem. Segundo o autor, um estudante autorregulado é capaz de estabelecer seus objetivos, automonitorar-se, bem como se autoavaliar em vários momentos durante o processo de construção do conhecimento. 
Para Murad (2005, p.24), “A auto-regulação faz das crianças pensadores maduros, que promovem experiências de conflito para si mesmas, questionam suas apropriações básicas, promovem contra-exemplos para as próprias regras, etc.” Especialmente em casos de alunos que apresentam dificuldades na aprendizagem, segundo Araújo (2009), Goti (1998), Jou e Sperb (2006), Ribeiro (2003) e Zimmerman (1990, 2002), é fundamental um ensino que favoreça o desenvolvimento de estratégias metacognitivas de autorregulação para que os alunos possam, de forma autônoma, construir e utilizar estratégias eficazes para a superação de problemas propostos nas tarefas escolares.

A prática do professor em sala de aula é fundamental a um ensino que favoreça aos alunos a reflexão sobre os seus próprios processos de aprendizagem, ou seja, os processos metacognitivos. Contudo, instrumentos de auxílio didático - como livros, textos e revistas, por exemplo - são fundamentais ao trabalho do professor, pois ajudam a nortear a sua ação, bem como à aprendizagem dos alunos.

As atividades propostas em um livro ou material didático podem ser de grande valia para uma aprendizagem promotora da metacognição - principalmente se considerarmos uma abordagem reflexiva do conhecimento, por parte do professor, enquanto mediador entre o saber e o aluno. Por outro lado, um material didático que não favoreça o uso de estratégias metacognitivas para a resolução das atividades propostas, pode trazer prejuízos à aprendizagem - principalmente se o professor pautar sua prática unicamente nas orientações e sugestões apresentadas nesse material.

Ao pesquisar o uso de estratégias metacognitivas no livro didático, Lucena (2013) verificou que o desenvolvimento de tais estratégias ocorreu com pouca frequência nos livros em que pesquisou. $\mathrm{O}$ autor investigou dois livros que tinham propostas metodológicas diferentes: um, considerado mais tradicional, priorizava o trabalho com exercícios de fixação de regras e procedimentos; o outro era considerado detentor de uma proposta mais inovadora. No livro considerado mais inovador a frequência de questões que poderiam viabilizar o uso de estratégias metacognitivas foi inferior a $8 \%$, enquanto que no livro considerado mais tradicional, a frequência foi de 4\%. Assim, segundo Lucena (2013), ambos os livros apresentam poucas atividades que podem favorecer o desenvolvimento da metacognição dos alunos em sua resolução. 


\section{A resolução de problemas e o conhecimento algébrico}

O ensino de Matemática na educação básica, muitas vezes, está permeado de valores educacionais não condizentes com a necessidade de uma aprendizagem que permita a construção do conhecimento, mas simplesmente por meio de memorizações, exercícios, repetições e assimilações mecânicas de conceitos. Contudo, para um efetivo aprendizado, fazse necessário ao aluno construir conceitos e não apenas assimilá-los.

Segundo Vigotski (2001), a construção de conceitos constitui um processo psicológico complexo, que busca entender e resolver problemas e que são fundamentais em todo o processo de aprendizagem. "O conceito não é tomado em seu sentido estático e isolado, mas nos processos vivos de pensamento, de solução de problema [...]” (p.165).

Para Onuchic e Allevato (2004), a resolução de problemas matemáticos favorece uma aprendizagem que leva o aluno a "pensar sobre" a construção de conceitos e procedimentos, bem como sobre o desenvolvimento do conhecimento matemático que ele precisa aprender, diferentemente da simples aplicação de conceitos prontos, como no caso da aplicação de exercícios de fixação. Sobre estes, D’Amore (2007) considera que suas resoluções consistem na utilização de regras e procedimentos já aprendidos, objetivando a verificação imediata ou o reforço do que foi fixado neste processo.

No que se refere ao "pensar sobre" durante a resolução de problemas, identificamos o favorecimento de reflexão sobre a própria aprendizagem. Compreendemos, então, que atividades propostas em livros ou materiais didáticos devem viabilizar uma aprendizagem reflexiva, contrapondo o automatismo presente em exercícios que favorecem uma assimilação do conteúdo matemático por meio de repetição de procedimentos.

Segundo Lester (1985), muitos professores têm a preocupação de treinar seus alunos em como usar procedimentos matemáticos para resolver atividades. Contudo, segundo o autor, mais do que saber como, os alunos devem saber quando e para que desenvolver determinados procedimentos, possibilitando, assim, o monitoramento de conhecimentos durante seu processo de construção.

Em se tratando do ensino-aprendizagem de álgebra, segundo Araújo (2009), é importante o uso de problemas como estratégia didática para abordar o conhecimento algébrico, bem como para a efetiva construção de conceitos, viabilizando o uso de estratégias metacognitivas.

O ensino de álgebra não deve se limitar à mera manipulação de expressões ou à apresentação de definições formais que não representem significados para os alunos. Faz-se necessário uma 
base cognitiva que os alicerce nessa aprendizagem, viabilizando a construção de significados para as tais expressões.

Para Kieran (2007 apud CANAVARRO, 2009), a álgebra não deve ser encarada apenas como uma técnica, mas principalmente como uma forma de pensamento e raciocínio acerca de situações matemáticas.

Dessa forma, entendemos que o foco da aprendizagem da álgebra não deve ser a simples manipulação de letras e números, mas, sim, o raciocínio, o pensamento, a reflexão que devem motivar o aluno a fazer uso da manipulação simbólica para resolver problemas matemáticos.

Segundo Canavarro (2009), o pensamento algébrico, portanto, é o processo pelo qual os alunos, a partir de um conjunto de casos particulares, podem vir a generalizar suas ideias matemáticas, fazendo uso da argumentação, podendo expressá-las de maneira mais formal.

Entendemos, então, que um ensino de álgebra eficaz não deve estar firmado apenas no cálculo literal e na manipulação de letras ou símbolos, mas o aluno deve compreender a linguagem algébrica escrita como sendo o resultado de processos que tiveram início com o pensamento algébrico.

Ao considerarmos o pensamento algébrico como uma habilidade de se refletir metacognitivamente, percebemos a possiblidade de o sujeito da aprendizagem desenvolver estratégias para a resolução de problemas, que não se limitarão à reprodução de procedimentos, cálculos e meras manipulações de expressões algébricas.

Por meio de uma abordagem algébrica reflexiva, em que o papel do aluno não se limita a reproduzir procedimentos nem assimilar conceitos prontos, é possível contribuir com o desenvolvimento do pensamento algébrico; viabilizar a tradução da linguagem natural para a linguagem algébrica; construir conceitos mediante a resolução de problemas, bem como criar estratégias metacognitivas no ensino-aprendizagem da álgebra.

Sabendo que as atividades de Matemática que compõem o objeto de pesquisa deste trabalho estão contidas no material didático do Gestar II, realizamos uma breve abordagem sobre o referido material. 


\section{O material didático de Matemática do Gestar II}

As ações do Gestar II estão baseadas em um material didático composto por 20 livros, por meio dos quais os professores cursistas devem utilizar as estratégias didáticas apresentadas para a implementação da proposta do programa nas escolas. No entanto, nem todos esses livros são utilizados pelo professor cursista diretamente para propor situações didáticas de resolução de questões em sala de aula.

Alguns livros são direcionados para os momentos presenciais de formação dos professores, como o Caderno do Formador e 6 Cadernos de Teoria e Prática (TP). Tem ainda o Guia Geral, caderno em que se encontra retratada toda a proposta pedagógica do Gestar II: o currículo, a ementa das disciplinas, as bases estruturadoras e metodológicas que regem o programa. Para uso em sala de aula, funcionando como uma espécie de livro didático, o programa apresenta 12 Cadernos de Atividades de Apoio à Aprendizagem (AAA), sendo 6 na versão do aluno e 6 na versão do professor - estes últimos funcionam como uma espécie de livro do professor, com respostas, orientações e sugestões de trabalho.

Nossa pesquisa, então, investigou as atividades de álgebra contidas nos AAA, versão do professor, por admitirmos que as orientações e sugestões de trabalho dadas ao professor cursista são fundamentais ao reconhecimento de estratégias metacognitivas.

\section{Metodologia}

Nosso trabalho buscou, primeiramente, analisar o material didático do Gestar II, a fim de fazer um levantamento das atividades de álgebra a serem investigadas. Assim, de acordo com a pré-análise que realizamos, os AAA contêm, no total, 658 atividades, que incluem diferentes conteúdos pertencentes a todos os campos do conhecimento matemático referentes aos anos finais do ensino fundamental. Destas 658 atividades matemáticas, analisamos apenas aquelas contidas em Unidades Didáticas (UD) direcionadas exclusivamente à álgebra, o que corresponde a 121 questões - o equivalente a, aproximadamente, 18\% das 658 atividades propostas nos AAA.

Ao analisarmos previamente as atividades, tivemos que considerar o fato de que elas não devem ser tratadas isoladamente, pois muitas delas foram elaboradas de forma interligada e estruturadas em um esquema que o programa chama de "Aula". Assim, nos AAA, cada UD é composta por 8 Aulas. Cada uma dessas Aulas é composta por várias atividades e, muitas vezes, a resolução de uma é pré-requisito para a resolução de outra. 
Após fazermos o levantamento das atividades de álgebra, buscamos identificar quais delas podem favorecer o uso de estratégias metacognitivas em sua resolução. Nessa segunda etapa, analisamos as atividades de álgebra pertencentes ao contexto de cada Aula, considerando as orientações dadas ao professor pelo próprio material. Assim, buscamos admitir as diversas possibilidades de resolução compatíveis com as competências e habilidades inerentes aos anos finais do ensino fundamental.

A terceira etapa da nossa pesquisa consistiu em classificar as atividades identificadas como promotoras da metacognição de acordo com as categorias de análise propostas por Araújo (2009) e Lucena (2013).

Em sua pesquisa, Araújo (2009) desenvolveu três categorias inerentes à dimensão de autorregulação e Lucena (2013), ao investigar a metacognição em livros didáticos, fazendo uso das categorias criadas por Araújo (2009), sentiu a necessidade de desenvolver outra categoria relativa à dimensão do conhecimento. A seguir, apresentamos as categorias.

- Estratégia metacognitiva de ordem pessoal: nesta categoria, desenvolvida por Araújo (2009), deveriam ser classificadas as atividades algébricas que favorecessem a autoavaliação por parte do aluno, vindo a permitir a reflexão sobre o seu desempenho em uma prova, sobre a necessidade de reforçar o estudo de algum conteúdo e de monitorar seu próprio conhecimento.

- Estratégia metacognitiva de ordem do procedimento: nesta categoria, foram classificadas as atividades cujas resoluções envolveram estratégias que favoreceram a tomada de consciência dos procedimentos utilizados pelos alunos, pois, segundo Araújo (2009), é possível aos alunos demonstrarem a compreensão de regras da Matemática para a resolução de problemas propostos.

- Estratégia metacognitiva de ordem da compreensão do problema: as atividades classificadas nesta categoria são aquelas em que suas resoluções, segundo Araújo (2009), estão diretamente ligadas aos processos de autorregulação do conhecimento e da compreensão mais generalizada do problema, que permitem ao aluno monitorar seus processos cognitivos durante a resolução, efetuando correções, julgando a adequação da resposta, podendo interromper a qualquer instante o processo de resolução e vindo também a realizar novas tentativas.

- Estratégia metacognitiva de ordem do conhecimento: de acordo com Lucena (2013), as atividades classificadas nesta categoria permitem ao aluno refletir sobre o que ele 
sabe a respeito de um determinado conteúdo (reflexão sobre o próprio conhecimento), sem, necessariamente, levá-lo a monitorar o próprio conhecimento para a resolução de uma atividade.

No transcorrer da nossa pesquisa, percebemos que algumas atividades poderiam ser classificadas simultaneamente em duas categorias, na categoria "Conhecimento" e na categoria "Compreensão do problema". Desse modo, sentimos a necessidade de classificar tais atividades em Estratégia metacognitiva da ordem do conhecimento e da compreensão do problema.

A seguir, na análise dos resultados, trazemos, como exemplo, quatro atividades que foram analisadas em nossa pesquisa.

\section{Análise dos resultados}

Em nossa análise, consideramos, ainda, a distinção que há entre a simples resolução de exercícios - de forma mecânica e por repetição - e a superação de um problema algébrico, o qual pode favorecer a reflexão do aluno sobre o seu próprio conhecimento, a elaboração das próprias estratégias de resolução, o monitoramento de sua cognição, enfim, o uso de estratégias metacognitivas.

Na primeira atividade que apresentamos, foi dado um pequeno texto sobre um dos programas do Serviço Social da Indústria (SESI) de São Paulo, conforme mostra a figura:

Figura 1 - Atividade 1, Aula 6: Equação fracionária, UD 21, AAA 6 (Versão do Professor).

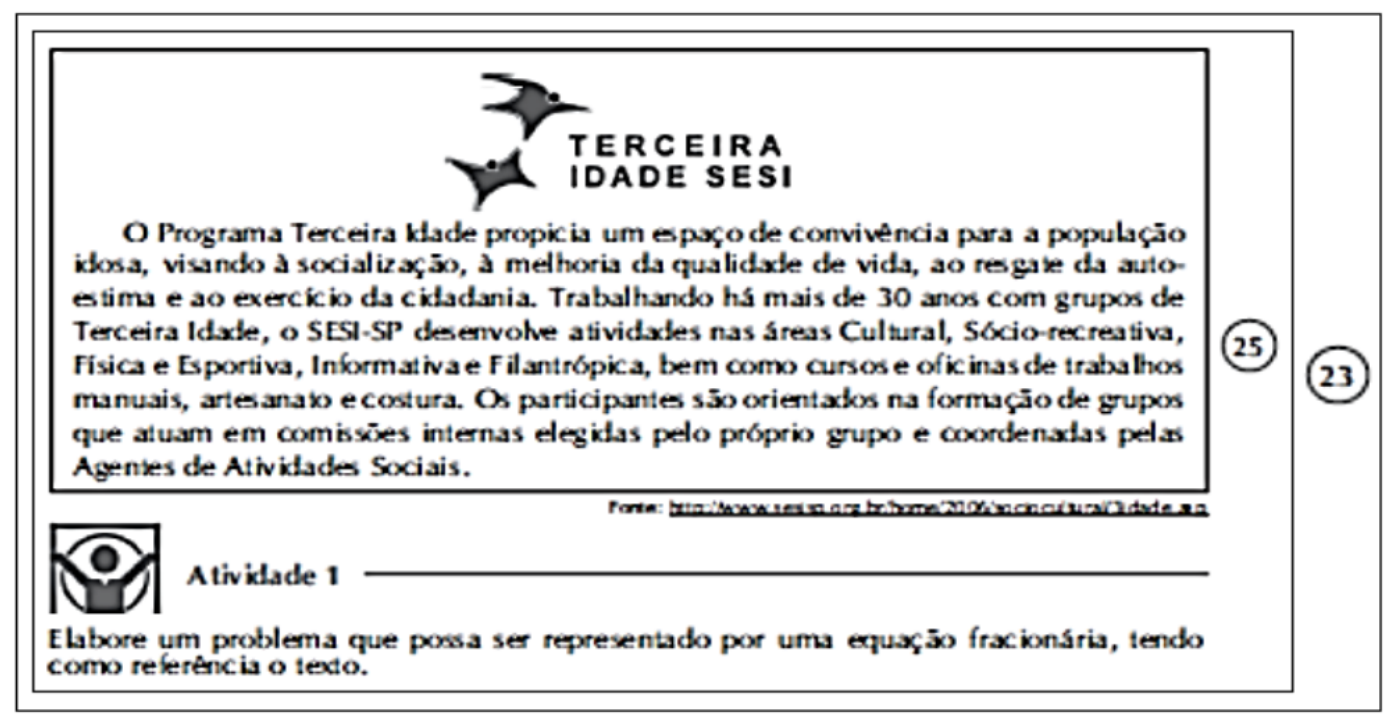

Fonte: Brasil (2008c, p.23). 
Para a Atividade 1, o aluno deverá tomar o texto como base para elaborar um problema que seja representado por uma equação fracionária. Por se tratar de uma equação que envolve frações, é provável que possa haver um maior grau de dificuldade durante a elaboração. Cabe ao professor orientá-lo, tendo cuidado para não interferir na reflexão e no desenvolvimento das estratégias criadas pelo aluno. Cabe ao professor também, levar o aluno a pensar sobre as informações contidas no texto, se são suficientes para a elaboração de um problema que possa ser representado por uma equação fracionária. Porém, apesar de considerarmos a necessidade da mediação do professor para a elaboração do problema solicitado na questão, analisamos a possibilidade de uma reflexão metacognitiva por parte apenas do aluno.

Para elaborar um problema que possa ser representado por uma equação fracionária, tomando o texto apresentado como referência (Figura 1), o aluno necessitará refletir sobre o próprio conhecimento. É possível até que o aluno venha fazer testes posteriores a fim de avaliar as possibilidades de resolução da questão. No entanto, antes de qualquer ação de monitoramento da própria cognição, far-se-á necessário ao aluno refletir sobre o que ele sabe acerca do seu conhecimento. Assim, classificamos essa primeira atividade em Estratégia metacognitiva da ordem do conhecimento.

A próxima atividade que apresentamos, está incluída no contexto de uma "Aula" que aborda sistemas de equação do $1^{\circ}$ grau com duas incógnitas, fazendo uso dos métodos da adição, comparação e substituição. Na referida "Aula", foram apresentadas, primeiramente, três atividades, em que os alunos são orientados a escolher, para a resolução de cada uma delas, dois dos métodos supracitados. Tais atividades não foram consideradas, em nossa pesquisa, como promotoras da metacognição, pois permitiam, ao aluno, resolvê-las seguindo procedimentos abordados anteriormente pelo professor. Assim, para resolver a próxima atividade, o aluno já deverá ter resolvido as atividades 1,2 e 3 que mencionamos.

Figura 2 - Atividade 4, Aula 5: Métodos algébricos, UD 23, AAA 6 (Versão do Professor).

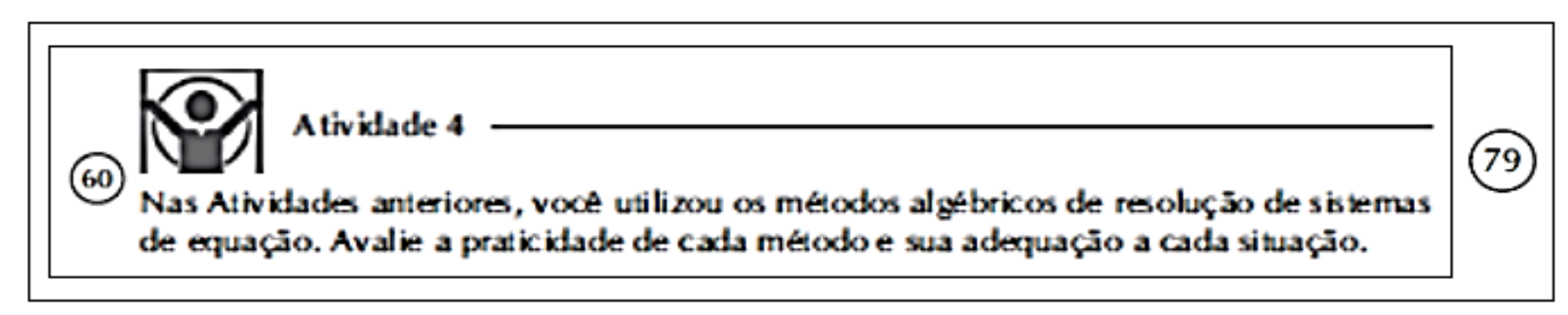

Fonte: Brasil (2008c, p.79). 
Mesmo não tendo refletido sobre a construção das próprias estratégias para a resolução das atividades anteriores, mas apenas aplicado procedimentos, agora, nessa atividade, o aluno é orientado a refletir sobre qual dos métodos utilizados anteriormente (adição, comparação e substituição) é o mais prático ou o que melhor se adequa a cada uma das situações. Logo, pela possibilidade de o aluno vir a refletir sobre os diferentes procedimentos utilizados nas questões anteriores, classificamos essa atividade em Estratégia metacognitiva de ordem do procedimento.

A próxima atividade, por alguma razão que desconhecemos, não consta no AAA do Professor. Assim, por constar apenas no material didático dos alunos, e considerando que estes têm acesso a tal questão, extraímos a Figura 3 da Versão do Aluno.

Figura 3 - Atividade 4, Aula 4: Relação entre tabelas e gráficos: expressando regularidades incluindo duas expressões, UD 12, AAA 3 (Versão do Aluno).

\section{Atividade 4}

Cristina e felipe väo para a ecola diariamente fazendo o seguinte percurso:

Crist ina: Caminha por 10 minuxos até o ponxo de Onibus. LS eppera por 5 minuxos e pega o Onibus. Percorre de Onibus 30 minuxos, desce e caminha por mais 15 minuxos ałe chegar a soola.

Felipe: Caminha por 15 minuxos e quando chega perto da escola corre cerca de 5 minutos.

Qual o gafico que melhor representa o percurso de Cris tina e o percurso de Felipe? Jus tifique suas respostas:

a)

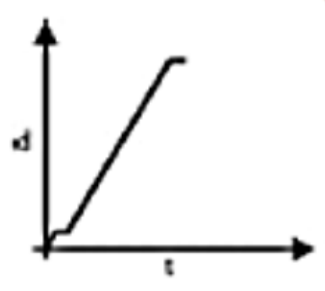

d)

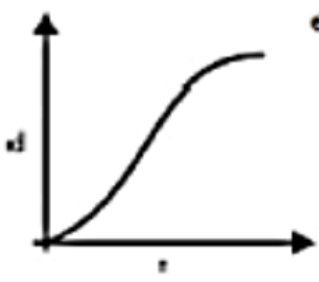

b)

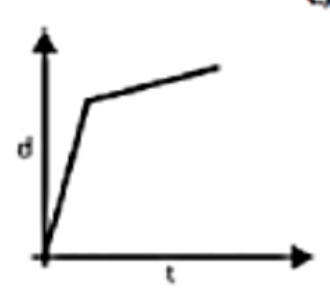

e)

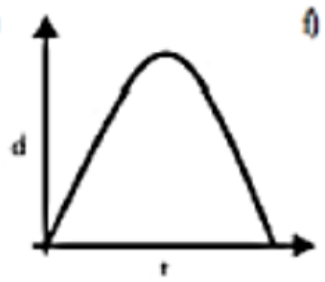

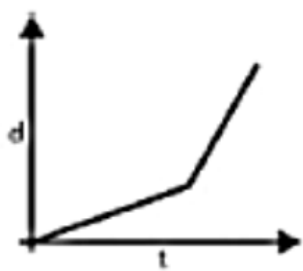

f)

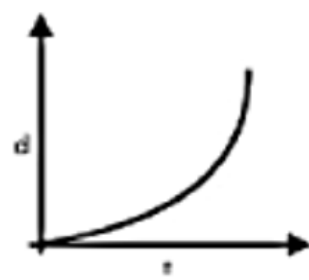

Fonte: Brasil (2008b, p.131).

Embora não esteja explícito no enunciado desta atividade, espera-se que o aluno venha a considerar a velocidade das duas crianças ao longo do percurso - o que vai indicar a inclinação das retas -, visto que, em dados intervalos de tempo, a velocidade pode ser maior, menor ou nula. 
Dos gráficos que constam na questão, nenhum representa exatamente a trajetória de Cristina e Felipe. Assim, o aluno terá que indicar aqueles que mais se aproximam de tais trajetórias conforme consta no enunciado: "o gráfico que melhor representa o percurso".

Segundo o que é solicitado na questão, além de indicar os gráficos, o aluno deverá justificar o porquê de sua escolha.

Para resolver a Atividade 4 (Figura 3), o aluno poderá perceber, por exemplo, que, nos intervalos em que as duas crianças percorreram certas distâncias em menor ou maior tempo ou, ainda, quando Cristina chega a parar por 5 minutos, houve variações na inclinação das retas em cada intervalo de tempo, o que sugere a ocorrência de aumento, diminuição ou nulidade da velocidade. Assim, ao tentar justificar sua resposta, o aluno poderá refletir sobre o conhecimento que tem a respeito das relações entre o tempo, a distância e a velocidade (estratégia metacognitiva da ordem do conhecimento).

Outro ponto importante que destacamos é o fato de que, por não haver precisão nas representações gráficas em relação às descrições dos percursos de Cristina e Felipe, o aluno poderá perceber tais incompatibilidades ${ }^{1}$, sendo possível, assim, fazer questionamentos acerca do problema como um todo, podendo, inclusive, monitorar seu conhecimento durante a resolução (estratégia metacognitiva de ordem da compreensão do problema).

Diante de tais percepções, consideramos que essa atividade pode ser classificada simultaneamente em duas categorias, Estratégia metacognitiva da ordem do conhecimento e da compreensão do problema.

A próxima atividade apresenta uma situação em linguagem natural e solicita que os alunos construam um sistema de equações (linguagem algébrica) e encontrem o valor de cada incógnita do sistema.

${ }^{1}$ Acreditamos que, para o aluno vir a ter tais percepções, seria fundamental o papel do professor como instigador de uma discussão que viabilize a reflexão diferenciada sobre o problema, pois é possível que o aluno, por si só, não venha a questionar a imprecisão dos gráficos. 
Figura 4 - Atividade 1, Aula 4: Situações-problema e sistemas de equações, UD 23, AAA 6 (Professor).

\section{Aula 4 \\ Situações-problema e sistemas de equações}

Objetivo

Resolver sis emas de equax̧ès utilizando diferentes métodos.

\section{Atividade 1}

Para uma confraternizagaio na empresa onde traba ha, André comprou dois sanduíches de metro e cinco garrafas de refrigerante, gastando R\$101,50. Para a mesma festa, Samuel comprou um sanduíche d: metro e oixo garrafas de refrigerante, gastando R\$63,40.

a) Construa um sistema de equaxièes que represente a situação.

b) Qual e o preço de cada sanduíche e de cada refrigerante?

Fonte: Brasil (2008c, p.76).

Esta atividade está incluída em uma sequência de "Aulas", nas quais foram realizadas várias abordagens sobre sistemas de equação do $1^{\circ}$ grau com duas incógnitas. Considerando as abordagens que foram realizadas, envolvendo transformação de um enunciado de um problema em linguagem algébrica, reconhecemos que houve situações com um grau maior de dificuldade. Assim, nesta Atividade, bastaria ao aluno - obedecendo ao raciocínio exposto na Seção 3 do TP correspondente - chamar os "sanduíches de metro" de "x" e as "garrafas de refrigerante" de "y", que poderia chegar às equações $2 x+5 y=101,50$ e $x+8 y=63,40$.

Para resolver o item "b", o aluno poderia usar os mesmos métodos utilizados nas abordagens anteriores, tratadas na Seção 3, encontrando, talvez, uma maior dificuldade apenas em procedimentos com operações algébricas pelo fato de as fórmulas apresentarem números decimais.

Compreendemos que, no item "a", a transformação do enunciado proposto, para a linguagem algébrica, não levaria o aluno a refletir sobre os próprios conhecimentos.

Apesar de o aluno poder vir a apresentar um maior grau de dificuldade na execução dos cálculos do item "b", não percebemos o desenvolvimento de estratégias metacognitivas que pudessem levá-lo a se automonitorar. Desse modo, não identificamos essa atividade como promotora da metacognição. 


\subsection{Discussão dos resultados}

Apresentamos na Tabela 1, a frequência absoluta das atividades que foram classificadas nas categorias de análise utilizadas em nosso trabalho:

Tabela 1: Frequência absoluta de Atividades de álgebra que favorecem a metacognição distribuídas por categorias de análise.

\begin{tabular}{lc}
\hline \multicolumn{1}{c}{ Estratégia metacognitiva } & $\begin{array}{c}\text { Quantidade de } \\
\text { Atividades } \\
\text { categorizadas }\end{array}$ \\
\hline Ordem pessoal & 0 \\
\hline Ordem do procedimento & 3 \\
\hline Ordem da compreensão do problema & 0 \\
\hline Ordem do conhecimento & 4 \\
\hline Ordem do conhecimento e da compreensão & 2 \\
do problema & 9 \\
\hline Total & \\
\hline
\end{tabular}

Do total de 121 Atividades algébricas analisadas, apenas 9 atividades foram classificadas nas categorias de análise, o equivalente a, aproximadamente, 7\% do total. Assim, considerando apenas as questões promotoras da metacognição, podemos observar no Gráfico 1 os percentuais por categorias:

Gráfico 1: Percentual das estratégias metacognitivas encontradas nas Atividades do material didático do Gestar II.

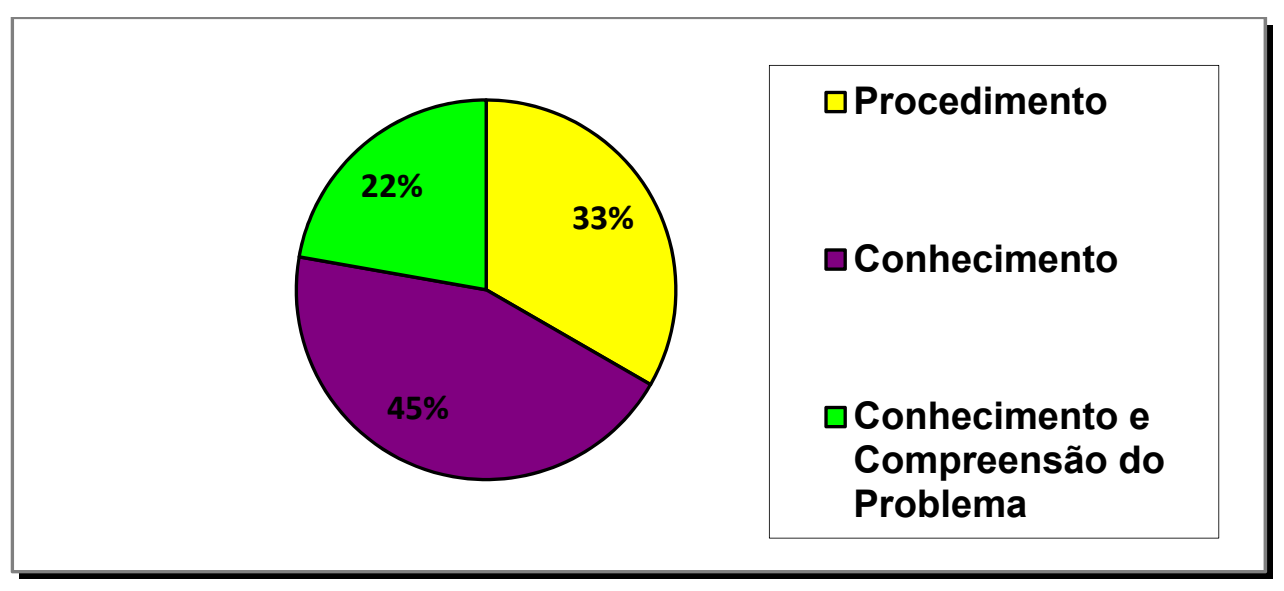


Das 9 atividades classificadas, quase metade corresponde à estratégia metacognitiva que permite ao aluno refletir sobre o próprio conhecimento, sem necessariamente precisar regulálo. Tais atividades não estão ligadas aos processos de resolução de problemas, em que o aluno poderá planejar estratégias, testar hipóteses, monitorar as etapas de resolução, avaliar a adequação ou não das respostas e buscar novos meios para superação do problema, mas estão ligadas apenas a uma análise reflexiva a respeito do que o aluno "sabe sobre" determinado conteúdo. Nesse tipo de atividade, não percebemos enunciados bem elaborados, mas apenas comandos do tipo "elabore um problema" e "justifique sua resposta". Assim, o aluno pode refletir sobre o seu conhecimento, mas não necessitou regular a sua cognição para o desenvolvimento de estratégias de superação de problemas.

De acordo com o Gráfico 1, um terço das atividades favorece a autorregulação de procedimentos matemáticos. Esse tipo de atividade, segundo a categoria de "Ordem do Procedimento" desenvolvida por Araújo (2009), está mais relacionada a procedimentos matemáticos, à execução de cálculos propriamente ditos. No entanto, em nosso trabalho, percebemos que das 3 atividades classificadas, duas relacionam-se ao monitoramento de processos matemáticos mais abstratos, como a generalização algébrica. O exemplo que apresentamos neste artigo, no entanto, permite apenas refletir e avaliar a praticidade e a adequação de procedimentos. Normalmente, atividades mais voltadas à execução de cálculos são mais comuns em livros de metodologias mais tradicionais.

Identificamos que, aproximadamente, $20 \%$ das atividades favorecem simultaneamente a metacognição nas dimensões de conhecimento e de autorregulação. Especificamente nas duas questões classificadas, no que se refere à dimensão do conhecimento, percebemos novamente comandos do tipo "justifique suas respostas" e "dê sua sugestão". No que se refere à dimensão de autorregulação, classificadas na categoria "Compreensão do Problema", percebemos algumas incompatibilidades entre o enunciado da questão e suas possíveis representações gráficas. Portanto, a possibilidade de os alunos virem a fazer tentativas de ajustes em tais incompatibilidades, levou-nos a classificar tais atividades na referida categoria de autorregulação. No entanto, não podemos afirmar que tais questões foram elaboradas com esse fim.

\subsection{Comparação dos resultados}

Ao pesquisar o uso de estratégias metacognitivas em dois livros didáticos do $6^{\circ}$ ano do ensino fundamental, Lucena (2013) identificou a baixa frequência de tais estratégias nos livros 
pesquisados. $\mathrm{O}$ autor investigou dois livros que tinham propostas metodológicas diferentes. $\mathrm{O}$ livro didático reconhecido como sendo de proposta mais inovadora, o autor denominou de LD 1. O livro de proposta mais tradicional, denominou LD 2.

A nossa pesquisa caminhou na direção da pesquisa realizada por Lucena (2013), em que buscamos identificar estratégias metacognitivas presentes em questões propostas em materiais didáticos. Assim, sentimos a necessidade de comparar os resultados da nossa pesquisa com os resultados apresentados pelo referido autor (atribuímos ao material didático do Gestar II a sigla $\mathrm{MDG})$ :

Tabela 2: Comparação com dados da pesquisa de Lucena (2013) - frequência de questões que favorecem a metacognição em materiais didáticos.

\begin{tabular}{cccc}
\hline $\begin{array}{c}\text { Material } \\
\text { Didático }\end{array}$ & $\begin{array}{c}\text { Total de atividades } \\
\text { pesquisadas }\end{array}$ & $\begin{array}{c}\text { Atividades que favorecem } \\
\text { a metacognição }\end{array}$ & Percentual \\
\hline LD 1 & 342 & 27 & $7,87 \%$ \\
\hline LD 2 & 421 & 17 & $4,03 \%$ \\
\hline MDG & 121 & 09 & $7,44 \%$ \\
\hline
\end{tabular}

Assim como Lucena (2013), identificamos uma baixa frequência de problemas matemáticos que favorecem ao desenvolvimento de estratégias metacognitivas no material didático do Gestar II.

Apesar de os LD 1, LD 2 e o MDG terem investigado quantidades diferentes de questões, procuramos estabelecer um comparativo entre o percentual de estratégias metacognitivas encontradas em nosso trabalho e no de Lucena (2013), conforme apresentamos no gráfíco abaixo: 
Gráfico 2: Comparação entre o percentual de estratégias metacognitivas encontradas nas atividades do LD 1, do LD 2 e do MDG.

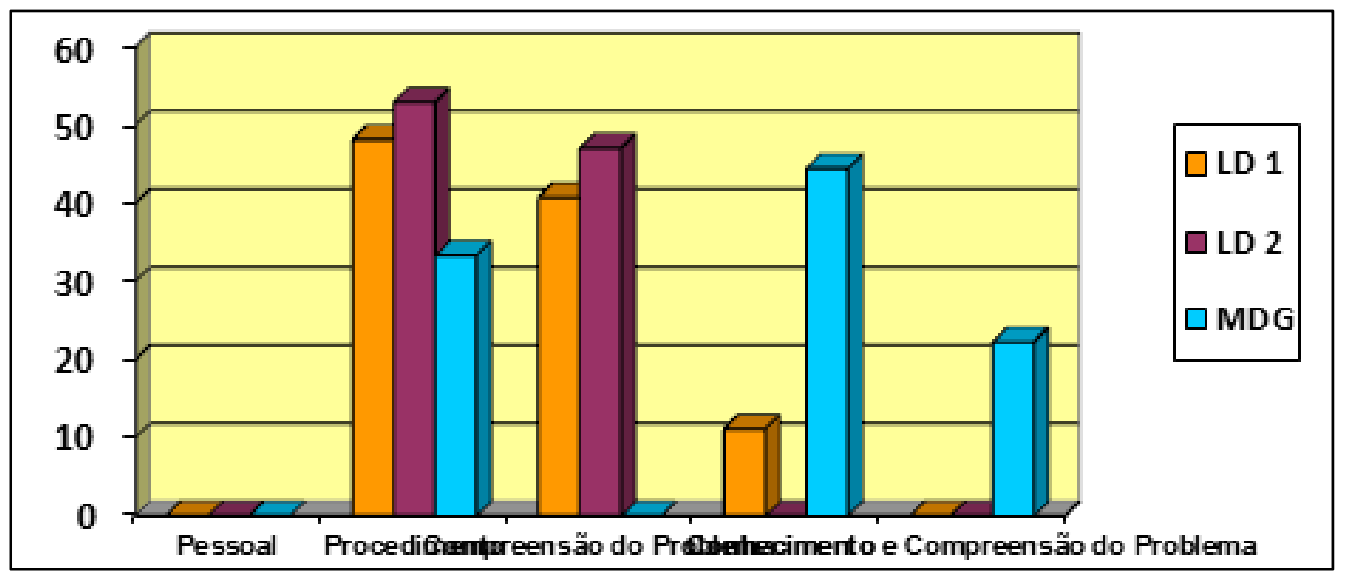

Ao fazermos a comparação por categorias de análise, percebemos que Lucena (2013) identificou uma maior prevalência da categoria de "Procedimento" no LD 2, livro considerado mais tradicional, enquanto que houve uma menor incidência no MDG. Questões que permitem uma maior execução de cálculos e procedimentos matemáticos, muitas vezes, ocorrem com maior frequência em livros de metodologia mais tradicional.

Referente à “Compreensão do Problema”, não identificamos em nosso trabalho atividades que pudessem ser classificadas exclusivamente em tal categoria, enquanto que Lucena (2013) pode identificá-la nos dois livros pesquisados. Normalmente, questões inerentes a essa categoria costumam ser mais bem elaboradas e viabilizam uma maior autorregulação da cognição. Assim, percebemos a deficiência do MDG em não trazer questões que possam favorecer a compreensão e a superação de problemas.

Em relação ao "Conhecimento", cuja categoria foi desenvolvida pelo próprio Lucena (2013), percebemos que houve uma incidência maior no MDG. Como já mencionamos, questões inerentes a essa categoria não demonstram maiores cuidados e melhores elaborações, não necessitam de um planejamento que possa levar o aluno a desenvolver as próprias estratégias de resolução de problemas, mas apenas, refletir acerca do que "se sabe sobre".

No que se refere à "Ordem Pessoal”, assim como em nosso trabalho, Lucena (2013) não identificou nenhuma atividade que pudesse ser classificada nessa categoria. Assim, é possível perceber que não é comum em materiais de auxílio didático atividades que levem o aluno a se autoavaliar. 
Lucena (2013) não identificou problemas que pudessem ser classificados em mais de uma categoria de análise, diferentemente do nosso trabalho, em que pudemos classificar duas questões em “Conhecimento e Compreensão do Problema”.

Percebemos que, assim como nos livros didáticos pesquisados por Lucena (2013), no material didático que investigamos houve prevalência absoluta de exercícios que propiciam respostas por meio do automatismo, da reprodução e repetição de estratégias de resolução, chegando a ultrapassar $90 \%$ de incidência.

\section{Considerações finais}

Segundo a proposta pedagógica do Gestar II, o programa está fundamentado na teoria socioconstrutivista e propõe um ensino-aprendizagem inovador, que prioriza a construção do conhecimento, pautando-se na superação de problemas, favorecendo a autonomia do aluno e viabilizando meios para a reflexão nos processos de aprendizagem.

Contrariando esta perspectiva, no material didático analisado, identificamos uma abordagem algébrica que pouco favorece a metacognição - considerando que o uso de estratégias metacognitivas para resolução de problemas matemáticos, consiste, justamente, em viabilizar, ao aluno, a reflexão sobre os próprios processos de construção do conhecimento, pensando sobre eles e/ou monitorando-os. Portanto, das 121 atividades analisadas, apenas 9 atividades foram consideradas promotoras da metacognição.

Dentre o pequeno quantitativo de atividades promotoras da metacognição encontradas, um terço está mais ligada a procedimentos de cálculos matemáticos, e quase metade permite ao aluno apenas refletir sobre o próprio conhecimento, sem, necessariamente, monitorá-lo.

No transcorrer da nossa pesquisa, encontramos alguns elementos que merecem ser melhor investigados. Um deles diz respeito à falta de clareza ou à possível ocorrência de equívocos quanto à elaboração dos enunciados de algumas atividades - corroborando, então, com a pesquisa de Souza (2011), a qual já havia destacado que o material didático de Matemática do Gestar II apresentava problemas no enunciado de algumas questões. Tais ocorrências merecem investigações mais aprofundadas, visto que atividades com esse tipo de problema podem vir a prejudicar uma aprendizagem que permita o desenvolvimento de estratégias metacognitivas.

Pesquisamos a metacognição no material didático de um programa de formação continuada do Ministério da Educação (MEC), voltado para professores dos anos finais do ensino 
fundamental, e não levamos em conta a prática docente dos profissionais participantes do referido programa. Contudo, reconhecemos que a prática docente é algo determinante nos processos de ensino-aprendizagem, e que o professor, no cotidiano escolar, pode não seguir à risca as sugestões do material. Pode, inclusive, conduzir suas aulas de forma mais dinâmica do que lhes é proposto, de modo a vir a favorecer os processos metacognitivos de ensinoaprendizagem.

\section{Referências}

ARAÚJO, L. F. Rompendo o contrato didático: a utilização de estratégias metacognitivas na resolução de problemas algébricos. 2009. 301 f. Tese (Doutorado em Educação) Universidade Federal de Pernambuco, Recife, 2009.

BRASIL. Secretaria de Educação Básica. Programa Gestão da Aprendizagem Escolar Gestar II. Guia Geral. Brasília: MEC/SEB, 2008a.

. Secretaria de Educação Básica. Programa Gestão da Aprendizagem Escolar Gestar II. Matemática: Atividades de Apoio à Aprendizagem 3 (AAA3), Versão do Aluno: Matemática nas formas geométricas e na ecologia. Brasília: MEC/SEB, 2008b.

Secretaria de Educação Básica. Programa Gestão da Aprendizagem Escolar -

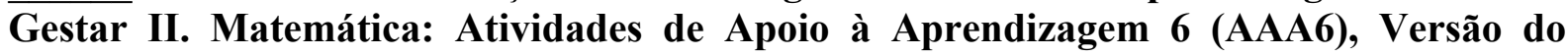
Professor: Matemática nas migrações e em fenômenos cotidianos. Brasília: MEC/SEB, $2008 \mathrm{c}$.

. Secretaria de Educação Fundamental. Parâmetros Curriculares Nacionais: terceiro e quarto ciclos do Ensino Fundamental: Matemática. Brasília, MEC/SEF, 1998.

BROWN, A. Metacognition, executive control, self-regulation, and other more mysterious mechanisms. In: WEINERT, F. E.; KLUWE, R. H. (Eds.). Metacognition, motivation, and understanding. Hillsdale, NJ: Lawrence Erlbaum Associates, 1987. p.65-116.

BURÓN, J. Enseñar a aprender: introdución a la Metacognición. 8. ed. Bilbao: Mensagero, 2002. (Recursos e instrumentos psicopedagógicos)

CANAVARRO, A. P. O pensamento algébrico na aprendizagem da Matemática nos primeiros anos. Quadrante, v.16, n.2, p.81-118, 2009. Disponível em: http://www.rdpc.uevora.pt/bitstream/10174/4301/1/_Quadrante_vol_XVI_2-2007pp000 pdf081-118.pdf. Acesso em: 5 out. 2013.

D’AMORE, B. Elementos de Didática da Matemática. 1. ed. São Paulo: Livraria da Física, 2007.

FIORENTINI, D. A pesquisa e as práticas de formação de professores de matemática em face das políticas públicas no Brasil. Bolema: Mathematics Education Bulletin = Bolema: Boletim de Educação Matemática, Rio Claro: UNESP, 2008, v.21, n.29, p. 43-70. 
FLAVELL, J. H. Metacognition and cognitive monitoring: a new area of cognitive developmental inquiry. American Psychologist, v.34, n.10, p.906-911, out./1979. Disponível em: http://www4.ncsu.edu/ jlnietfe/Metacog_Articles_files/Flavell\%20(1979).pdf. Acesso em: 29 set. 2013.

Speculations about the nature and development of metacognition. In: WEINERT, F. E.; KLUWE, R. H. (Eds.). Metacognition, motivation and understanding, Hillsdale, NJ: Lawrence Erlbaum Associates, 1987. p.21-29.

GERRIKAETXEBARRIA, J. X. U. La orientación metacognitiva: um estudio sobre la capacidad transferencial de la metacognición y su influencia en el rendimiento intelectual. Revista de Psicodidáctica, Vitoria-Gasteiz, ESP: Escuela Universitaria de Magisterio, n.1, 1996, p.27-53.

GOTI, M. C. Metacognición y motivación en el aula. Revista de Psicodidáctica, n.6, p.99107, 1998.1 Disponível em: http://www.ehu.es/ojs/index.php/psicodidactica/article/viewFile/81/77\#page=100. Acesso em: 28 nov. 2013.

JOU, G. I.; SPERB, T. M. A metacognição como estratégia reguladora da aprendizagem. Psicologia: Reflexão e Crítica, Porto Alegre, 19(2), p.177-185, 2006.

LAFORTUNE, L.; SAINT-PIERRE, L.; A afectividade e a metacognição na sala de aula. 1. ed. Lisboa, Portugal: Instituto Piaget, 1996. (Horizontes Pedagógicos)

LESTER, Frank K. et al. Methodological considerations in research on mathematical problem-solving instruction. Teaching and learning mathematical problem solving: Multiple research perspectives, p. 41-69, 1985.

LUCENA, A. M. A metacognição no livro didático de Matemática: um olhar sobre os números racionais. 2013. 152 f. Dissertação (Mestrado em Ensino das Ciências) Universidade Federal Rural de Pernambuco, Recife, 2013.

MARTINELLI, E. L. O impacto do programa Gestar II de Matemática na atividade docente, no estado de Tocantins inserido na região amazônica. 2009. 316 f. Dissertação (Mestrado em Educação) - Universidade de Brasília, Brasília, 2009. Disponível em: http://repositorio.unb.br/bitstream/10482/8661/1/2009_ElidioLuizMartinelli.pdf. Acesso em: 18 out. 2013.

MURAD, R. R. Auto-avaliação e avaliação do parceiro: estratégias para o desenvolvimento da metacognição e o aperfeiçoamento do processo de ensino-aprendizagem. 2005. $123 \mathrm{f}$. Tese de Doutorado - Pontifícia Universidade Católica, São Paulo, 2005. Disponível em: http://www.sapientia.pucsp.br/tde arquivos/23/TDE-2005-03-23T10:59:15Z339/Publico/teseraissa.pdf. Acesso em: 15 set. 2013.

ONUCHIC, L. R.; ALLEVATO, N. S. G. Novas reflexões sobre o ensino-aprendizagem de Matemática através da Resolução de Problemas. In: BICUDO, M. A. V.; BORBA, M. C. (Orgs.). Educação Matemática: Pesquisa em Movimento. São Paulo: Cortez, 2004. p.213231. 
RIBEIRO, C. Metacognição: um apoio ao Processo de aprendizagem. Psicologia: Reflexão e Crítica, 16(1), p.109-116, 2003.

SORO, P. M. B. Estrategias metacognitivas y de aprendizaje: estudio empírico sobre el efecto de la aplicación de un programa metacognitivo, y el dominio de las estrategias de aprendizaje en estudiantes de E.S.O, B.U.P y Univesidad. 2001. 333 f. Tesis (Doctoral en Educación) - Universidad Complutense de Madrid, Madrid, 2001.

SOUZA, J. M. S. Álgebra escolar na EJA: análise de uma sequência de aulas do Programa GESTAR II. 2011. 97 f. Dissertação (Mestrado em Ensino das Ciências) - Universidade Federal Rural de Pernambuco, Recife, 2011.

VIGOTSKI, L. S. A construção do pensamento e da linguagem. 1. ed. São Paulo: Martins Fontes, 2001. (Psicologia e Pedagogia)

WITTER, G. P.; WUO, W.; MORAIS, A. Capacitação Docente: níveis de formação. In: WITTER, G. P.; WUO, W. (Orgs.). Ensino de Ciências e Matemática: formação e atuação de professores. Cotia, SP: Ateliê, 2011. p.75-100.

ZIMMERMAN, B. J. Becoming a self-regulated learner: An overview. Theory into practice, v. 41, n. 2, p. 64-70, 2002. Disponível em: http://commonsenseatheism.com/wpcontent/uploads/2011/02/Zimmerman-Becoming-a-self-regulated-learner.pdf. Acesso em: 22 out. 2013.

. Self-regulated learning and academic achievement: an overview. Educational psychologist, v. 25, n. 1, p. 3-17, 1990. Disponível em: http://www.unco.edu/cebs/psychology/kevinpugh/motivation_project/resources/zimmerman9 0.pdf. Acesso em: 29 nov. 2013. 